\title{
Obtaining informed consent from study participants and results of field studies. Methodological problems caused by the literal treatment of codes of ethics
}

\begin{abstract}
The article discusses the issue of the necessity of obtaining informed consent from an individual who is to be a participant in an experiment. Codes of ethics concerning the behaviour of a psychologist fundamentally do not permit conducting experiments without informing their participants in advance that they will be conducted. Meanwhile, the act of obtaining prior consent (and thus of informing the study participant that they will be taking part in an experiment) can have a significant impact on results. The article describes an experiment in the field of social influence psychology during which one group was asked for their informed consent to participate in a study, while the second was simply presented with the main request (to sign a letter to the mayor about reducing the number of parking spaces for the disabled). The results demonstrate the strong influence of awareness that a study is being conducted on the decisions taken in the course of the experiment.
\end{abstract}

Key words: social influence, informed consent, ethics in experimentation

The concept of informed consent is primarily associated with clinical studies (Faden \& Beauchamp, 1986; Farrell et al., 2014; Ferrer et al., 2016), in which e.g. experimental therapy or studies of human behaviour at the physiological level are conducted. However, obtaining some form of confirmation that individuals are aware of their involvement in psychological studies involving e.g. observation of experimental participants' behaviour is frequently expected from the experimenter. Some journals (e.g. Frontiers in Psychology, Intelligence, Emotion) require that an article describing studies be accompanied by a copy of the informed consent form presented to study participants. While it is difficult to question the importance of such a document in respect of clinical trials (examining the effectiveness of a new pharmaceutical or therapy, or form of psychotherapy), the non-negotiable requirement to obtain informed consent from participants in all types of psychological studies would seem difficult in practice or, to put it differently, with the assumption that informed consent must be obtained, it becomes difficult to conduct studies in many areas of psychology.

Let us review the manner in which informed consent is defined by the APA (American Psychological Association, 2002):

\begin{abstract}
"Informed Consent, psychologists inform participants about (1) the purpose of the research, expected duration and procedures; (2) their right to decline to participate and to withdraw from the research once participation has begun; (3) the foreseeable consequences of declining or withdrawing; (4) reasonably foreseeable factors that may be expected to influence their willingness to participate such as potential risks, discomfort or adverse effects; (5) any prospective research benefits; (6) limits of confidentiality; (7) incentives for participation; and (8) whom to contact for questions about the research and research participants' rights. They provide opportunity for the prospective participants to ask questions and receive answers." (APA Code of Conduct, 8.02).
\end{abstract}

However, this document also allows for several exceptions from the principle of informed consent, as we can see in 8.05:

\footnotetext{
"Psychologists may dispense with informed consent only (1) where research would not reasonably be assumed to create distress or harm and involves (a) the study of normal educational practices, curricula, or classroom management methods conducted in educational settings; (b) only anonymous questionnaires, naturalistic observations or archival research for which disclosure of responses
}

\footnotetext{
* SWPS University of Social Sciences and Humanities, Faculty of Psychology in Wroclaw, Ostrowskiego 30 B, Wroclaw, Poland, tgrzyb@swps.edu.pl
} 
would not place participants at risk of criminal or civil liability or damage their financial standing, employability or reputation, and confidentiality is protected; or (c) the study of factors related to job or organization effectiveness conducted in organizational settings for which there is no risk to participants' employability, and confidentiality is protected or (2) where otherwise permitted by law or federal or institutional regulations."

We therefore see that the code of conduct permits omitting informed consent from participants when the study does not (or it is at least difficult to assume that it will cause) harm to the participant and AT THE SAME TIME is associated with one of the listed areas of study (the study of normal educational practices, curricula, or classroom management methods conducted in educational settings). We can therefore see that those rules do not permit conducting field experiments in social influence techniques (as these involve manipulation, while the code of conduct makes mention only of naturalistic observation).

In certain situations the code of conduct allows for hiding the real purpose of the study from participants - in 8.07 we may read that:

“(a) Psychologists do not conduct a study involving deception unless they have determined that the use of deceptive techniques is justified by the study's significant prospective scientific, educational or applied value and that effective nondeceptive alternative procedures are not feasible.

(b) Psychologists do not deceive prospective participants about research that is reasonably expected to cause physical pain or severe emotional distress.

(c) Psychologists explain any deception that is an integral feature of the design and conduct of an experiment to participants as early as is feasible, preferably at the conclusion of their participation, but no later than at the conclusion of the data collection, and permit participants to withdraw their data."

We can therefore see that in certain situations it is permissible to deceive participants as to the real purpose of a study (although not in cases of studies which could potentially cause emotional stress or physical pain); nevertheless, such a situation should be an exception rather than the rule. What is more, after completion of the study those individuals who have been deceived should have the right to demand removal of their data from study records. It would, however, seem that while the provisions of the Code of Conduct are well-known in the USA, researchers do not always observe them. One example is that of the unusual experiment conducted on an unimaginable sample of 61 million users of Facebook (Bond et al., 2012). In the study, the researchers attempted to impact turnout during elections in 2010 in the USA through various types of information presented to users (for example, suggesting that their acquaintances had voted en masse). It should be observed that this experiment not only failed to provide participants with the freedom to participate or not, but also had a real impact on social life (it may have even influenced election results). The researchers emphasized that the type of communication influenced not only the decision of the participants to vote or not, but also their relatives and friends. Another example comes from studies on obedience in the Milgram paradigm (Milgram, 1974). It is very well known that a key element in the experiment, regardless of the specifics of the procedure applied (Burger, 2009; Dolinski \& Grzyb, 2017; Perry, 2013) consists in deceiving the participant - uncovering the real purpose of the study would disrupt it and deprive it of all sense.

The solutions adopted in Poland are similar to those functioning in the USA. The Professional Code of Conduct of the Polish Psychological Society contains a portion titled "The psychologist as researcher" (paragraphs 29 to 42). A significant number of these paragraphs are rather general in nature, pointing to the important role of the psychologistas-researcher, the significant responsibility inherent in such work and publication of the results, and - of course - the duty to observe high ethical standards. Naturally, it is difficult to argue with this. However, several passages in that portion of the Professional Code of Ethics incline us to deep reflection, particularly from the perspective of an experimenter engages in field experiments. In particular this concerns paragraphs 29 to 31 . Let us take a look at 29:

29. The psychologist observes the principle of voluntary participation in psychological experiments, and also respects the right of participants to withdraw at any time from further participation in a study. If the participants of a study are involved in a hierarchical relationship with the researcher (i.e. as students, clients or employees), and also when there is the potential for social pressure to participate to be exerted, particular care should be taken to ensure the principle of voluntary participation is not violated.

This provision is clear - if a psychologist-researcher wishes to respect the principle of voluntary participation, the consent of the participant must be obtained. This means that every potential participant in a study must be informed without exception that an experiment is going to take place, and the researcher will most likely need to clear up any doubts as to the procedure itself, as well as record the consent in some form (in writing or orally). And again it may be assumed that in spite of their awareness of this rule, many researchers are not particularly observant of it. In the official journal of the Society, "Psychological Review" (Polish: "Przegląd Psychologiczny") one may find articles with descriptions of experimental studies that deceive their participants (for example: Kryś, Świderski, 2014).

Here it should be stated in no uncertain terms from the perspective of a researcher engaged in field studies: the full provision to participants of information about the purpose and the course of the experiment renders field studies in many areas of psychology utterly worthless. This has been common knowledge for a long time, at least since the experiments of Orne (Orne, 1962). Particularly 1970s and 1980s abounded in experiments examining the effect of providing complete information on the course of the study and obtaining informed consent from participants on produced results (Adair, Dushenko, \& Lindsay, 1985; Lueptow, Mueller, Hammes, \& Master, 1977; Spohn \& 
Fitzpatrick, 1980). E.g., a very interesting study by Resnick and Schwartz examined the effect of complete information regarding the course of the study on participants in a laboratory experiment on conditioning (Resnick \& Schwartz, 1973). The study revealed significant differences between the informed group and the uninformed group what is interesting, it was the uninformed group, which behaved in the manner confirming the hypotheses resulting from the earlier experiments.

It needs to be pointed out though that the abovementioned examples pertained exclusively to laboratory experiments and not those carried out in a natural surrounding. We thus asked ourselves the question of what effects would result from observing to the letter the provisions of the ethics codes and APA Code of Conduct, and we performed an experiment in which we obtained informed consent to participation in the field study. The experiment was based on a classic model for conducting studies in the psychology of social influence (Cialdini et al., 2006; Doliński, Grzyb, Olejnik, Prusakowski, \& Urban, 2002). The assumption was that once the participants have been informed that a study was being carried out (and once they have granted their consent), they would help the assistant of the experimenter more readily.

\section{Method}

Participants were passers-by in the vicinity of the main railway station in Wrocław. The day of the week and time for conducting the study were chosen at random (from between 9:00am and 5:00pm). Participants were selected for the study by counting every fifth person who had no opportunity to observe the interaction with the preceding participant. Random number tables were also used to create a randomization list assigning participants to either the experimental or the control group.

The primary request in the study was a question about agreement with a proposal to reduce the number of parking spaces for the disabled in Wrocław (one of Poland's main cities with nearly 650,000 residents) and making them available to all drivers. The request was deliberately formed in an unclear manner, requiring the participants to think a bit. Indeed, there is no particular reason not to agree with the proposal to provide more parking spaces (the vast majority of residents have experienced the problem of finding parking in the downtown), but the information that this would come at the expense of disabled drivers makes it slightly problematic from the ethical perspective.

The experimenter posed the following to the control group participants:

"Hello. As a resident of Wroctaw, I'm collecting signatures on a petition to the mayor asking him to reduce the number of parking spaces for the disabled. The idea is to have more spaces in the city for other drivers, because there's frequently not enough of them. Would you sign such a petition?"
Next, after hearing the response (affirmative or negative), he then added:

"I've also got copies of a letter to the mayor concerning this issue. You can take them and distribute them among your friends. How many will you take?"

The purpose of this was to collect data on two different types of variables: dichotomous and interval.

Participants in the control group heard the request at once, but in the experimental group it was preceded by a short interaction with the experimenter's assistant. A moment before the interaction proper he approached the participant and said:

"Excuse me, I've got a request, I am a psychology student and I'm doing a study for my MA thesis. In a moment, someone will approach you and ask you for a small favour. This is a small psychological experiment, and you can withdraw from it at any moment. There is no money involved, you either agree or not. It won't take more than a minute or two. Do you agree to participate?"

If consent was obtained (as in almost $70 \%$ of cases), the experimenter's assistant left, and around 30 seconds later the experimenter appeared and began the procedure described above. Two male and two female experimenters alternated performing the role at random. A total of 60 participants were involved (30 in each of the experimental conditions), and half of each group consisted of women.

\section{Results}

First it was checked whether the experimenter affected the results generated; analysis confirmed that there was no such influence. There was also no effect of participant's sex (both when examined alone and in interaction with experimenter's sex).

It was examined how information about participation in an experiment affected the decision to sign the petition - the percent of those agreeing and refusing in each group are presented in the Table below, which also contains the average values and standard deviations for the number of letters taken to give friends and acquaintances.

Table 1. Decisions on signing the petition and average number of letters taken for friends and acquaintances

\begin{tabular}{lccc}
\hline & & \multicolumn{2}{c}{ Group } \\
\cline { 2 - 4 } & & Informed & $\begin{array}{c}\text { Not } \\
\text { informed }\end{array}$ \\
\hline \multirow{2}{*}{ Decision } & Agree & $66.7 \%$ & $46.7 \%$ \\
\cline { 2 - 4 } & Refuse & $33.3 \%$ & $53.3 \%$ \\
\hline $\begin{array}{l}\text { Average and SD } \\
\text { of letters taken } \\
\text { for acquaintances }\end{array}$ & Average & 4.45 & 1.32 \\
\cline { 2 - 4 } & SD & 5.24 & 2.71 \\
\hline
\end{tabular}


The difference concerning the decision to support was statistically significant $\left(\chi^{2}(1)=4.887 ; p<0.05\right.$; $\phi=0.202$, Cohen's $d=0.534)$. It was also examined whether both groups differed in the amount of letters taken for acquaintances - the difference recorded was statistically significant $(t(58)=2.91 ; p=0.005$, Cohen's $d=0.75)$. In both tests, the group which had been informed about their participation in the experiment was more willing to help.

\section{Discussion}

As can be observed, the achieved results clearly demonstrate increased readiness to help among participants in the group of those informed of their participation in the study. There are several possible explanations for this effect. The first of them is the possibility of the presence of the "foot-in-the-door" effect (Freedman \& Fraser, 1966). This effect may have occurred due to the fact that the request to sign the petition came second (the participant had already agreed to participate in the experiment). This shows us the first problem associated with the necessity of obtaining consent to participate in a study: in this manner we have a group already marked by the earlier consent to participate in the experiment. Another reason is the fact of selection: a portion of potential participants approached about participation in the study refused. This means that the study itself was already drawing from a pool of preselected individuals, and the criteria for selection (readiness to help) was strongly related to the dependent variable later analysed, and impacted the results generated. It is worth keeping in mind that the occurrence of such a phenomenon very seriously damages the accuracy of the experiment. It should also be remembered that a significant portion of the study (particularly concerning social influence) operationalizes the dependent variable as some form of assistance, fulfilling a request, or consenting to perform a task proposed by the experimenter. A situation in which information about the conducted study "filters out" a group of those potentially ready to decline the request artificially alters the results of our study.

It should also be kept in mind that participants in the two groups performed entirely different roles. In the control group they were normal passers-by, approached on the street by a man or woman asking them to sign a petition - this is relatively common in large cities and does not evoke any particular emotional reaction, it is a situation to which passers-by are accustomed and they treat it as a normal occurrence. In the experimental group, however, after giving consent they became PARTICIPANTS, with all of the attendant consequences. What are they? For example, those written about by Milton Rosenberg (Rosenberg, 1965) and Stephen Weber and Thomas Cook (Weber \& Cook, 1972). Specifically, I refer to apprehension in the face of the judgement that can occur (and is frequently expected) from the researcher, and the particular capacity of a participant to guess the research hypotheses and then conform to them. In other words, people participating in a study feel the need to be a "good participant" - and thus one whose participation in the experiment helps the researcher in confirming (and not only falsifying) the research theses. Years of experience $n$ conducting laboratory experiments allow the author to state that the questions "how did I do?", "did I do everything right?" and "were my results ok?" are, firstly, very frequent among participants, and secondly, they clearly demonstrate that the participant is generally just a good and helpful person who wants to "do well". This "doing well", however, is significantly different from the natural behaviour that participants are typically asked to display.

It should also be emphasized that insofar as a portion of studies in social psychology can be conducted in the laboratory, there will always be a certain portion of them which require analysis of real behaviours in a real environment. The problems associated with abandoning this type of study have been detailed by Robert Cialdini (Cialdini, 2009) and Roy Baumeister et al. (Baumeister, Vohs, \& Funder, 2007). It has also been shown in earlier studies (Grzyb, 2016) that some of the areas of social psychology (particularly social influence) must be examined in real conditions, otherwise their results are nothing more than artefacts which bring little to nothing to science. The last element, strongly connected with the "two realisms", seems to be of particular significance (Aronson \& Carlsmith, 1968) in experimental studies. The lack of what Aronson and Carlsmith referred to as "mundane realism" can be the factor which questions the analyses of accuracy of laboratory studies.

The "intermediate variant", in the case of which the participants in the study are informed that the events they are participating in are in fact an experimental procedure but remain unaware of the actual nature of the procedure, should be also noted. For example, the metaanalysis of almost one thousand studies from such magazines as Journal of Personality and Social Psychology or Journal of Experimental Social Psychology shows that as far as the independent variable is concerned, true and complete information was provided only in $3 \%$ of the studies, whereas for the dependent variable, the value was $21 \%$ (Menges, 1973). One should bear in mind though that the study by Menges encompassed the period prior to the implementation of APA Code of Conduct. Present-day textbooks for psychological studies (f.e. Jackson, 2015) are much stricter in this respect and allow providing participants with incomplete information on the nature of the study only if they are offered the possibility of withdrawing from the experiment at any given moment.

The results obtained through the described experiment clearly indicate that in case of selected types of studies, obtaining informed consent from the participants is pointless due to the immense effect on the obtained results. This does not, of course mean that we should allow psychological experimenters to engage in any and all sorts of manipulations applied in every condition - it would seem that the decision to permit a departure from the principle of informed consent should be taken in cooperation with the appropriate research ethics committees. However, the phrase "in cooperation with" should be emphasized: as can be assumed, the best results will come from a process in 
which both sides (the researcher and the ethics commission taking the decision about the research) will be inclined to review the study design free from bias. Both those resulting from the "father effect" of the researcher towards their own idea, and those associated with a literal interpretation of code of ethics provisions. Such an attitude can lead to better research projects accounting for both the welfare of participants and the interests of science.

\section{References}

Adair, J.G., Dushenko, T.W., \& Lindsay, R.C. (1985). Ethical regulations and their impact on research practice. American Psychologist, 40(1), 59.

American Psychological Association. (2002). Ethical principles of psychologists and code of conduct. American Psychologist, 57(12), 1060-1073.

Aronson, E., \& Carlsmith, J.M. (1968). Experimentation in social psychology. The Handbook of Social Psychology, 2(2), 1-79.

Baumeister, R.F., Vohs, K.D., \& Funder, D.C. (2007). Psychology as the science of self-reports and finger movements: Whatever happened to actual behavior? Perspectives on Psychological Science, 2(4), 396-403.

Bond, R.M., Fariss, C.J., Jones, J.J., Kramer, A.D., Marlow, C., Settle, J.E., \& Fowler, J.H. (2012). A 61-million-person experiment in social influence and political mobilization. Nature, 489(7415), 295-298.

Burger, J.M. (2009). Replicating Milgram: Would people still obey today? American Psychologist, 64(1), 1.

Cialdini, R.B. (2009). We have to break up. Perspectives on Psychological Science, 4(1), 5-6.

Cialdini, R.B., Demaine, L.J., Sagarin, B.J., Barrett, D.W., Rhoads, K., \& Winter, P.L. (2006). Managing social norms for persuasive impact. Social Influence, 1(1), 3-15. https://doi.org/10.1080/15534510 500181459

Dolinski, D., \& Grzyb, T. (2016). One Serious Shock Versus Gradated Series of Shocks: Does "Multiple Feet-in-the-Door" Explain Obedience in Milgram Studies? Basic and Applied Social Psychology, 1-8. https://doi.org/10.1080/01973533.2016.1214836

Doliński, D., Grzyb, T., Folwarczny, M., Grzybała, P., Krzyszycha, K., Martynowska, K., \& Trojanowski, J. (2017). Would you deliver an electric shock in 2015? Obedience in the experimental paradigm developed by Stanley Milgram in the 50 years following the original studies. Social Psychological and Personality Science, doi: $10.1177 / 1948550617693060$
Doliński, D., Grzyb, T., Olejnik, J., Prusakowski, S., \& Urban, K. (2002). Dialog jako metatechnika wpływu społecznego. Tryb komunikacji a efektywność techniki "liczy się każdy grosz". Studia Psychologiczne, 40(3), 127-152.

Faden, R.R., \& Beauchamp, T.L. (1986). A history and theory of informed consent. Oxford University Press.

Farrell, E.H., Whistance, R.N., Phillips, K., Morgan, B., Savage, K., Lewis, V., ... Edwards, A. (2014). Systematic review and meta-analysis of audio-visual information aids for informed consent for invasive healthcare procedures in clinical practice. Patient Education and Counseling, 94(1), 20-32.

Ferrer, R.A., Stanley, J.T., Graff, K., Klein, W.M., Goodman, N., Nelson, W.L., \& Salazar, S. (2016). The Effect of Emotion on Visual Attention to Information and Decision Making in the Context of Informed Consent Process for Clinical Trials. Journal of Behavioral Decision Making, 29(2-3), 245-253.

Freedman, J.L., \& Fraser, S.C. (1966). Compliance without pressure: the foot-in-the-door technique. Journal of Personality and Social Psychology, 4(2), 195.

Grzyb, T. (2016). Why can't we just ask? The influence of research methods on results. The case of the "bystander effect." Polish Psychological Bulletin, 47(2). https://doi.org/10.1515/ppb-2016-0027

Jackson, S.L. (2015). Research methods and statistics: A critical thinking approach. Cengage Learning.

Lueptow, L., Mueller, S.A., Hammes, R.R., \& Master, L.S. (1977). The impact of informed consent regulations on response rate and response bias. Sociological Methods \& Research, 6(2), 183-204.

Menges, R.J. (1973). Openness and honesty versus coercion and deception in psychological research. American Psychologist, 28(12), 1030.

Milgram, S. (1974). Obedience to authority. An Experimental View. Harper, New York.

Orne, M.T. (1962). On the social psychology of the psychological experiment: With particular reference to demand characteristics and their implications. American Psychologist, 17(11), 776.

Perry, G. (2013). Behind the shock machine: The untold story of the notorious Milgram psychology experiments. The New Press

Resnick, J.H., \& Schwartz, T. (1973). Ethical standards as an independent variable in psychological research. American Psychologist, 28(2), 134.

Rosenberg, M.J. (1965). When dissonance fails: On eliminating evaluation apprehension from attitude measurement. Journal of Personality and Social Psychology, 1(1), 28.

Spohn, H.E., \& Fitzpatrick, T. (1980). Informed consent and bias in samples of schizophrenic subjects at risk for drug withdrawal. Journal of Abnormal Psychology, 89(1), 79.

Weber, S.J., \& Cook, T.D. (1972). Subject effects in laboratory research An examination of subject roles, demand characteristics, and valid inference. Psychological Bulletin, 77(4), 273. 